\title{
Focal Spot Size
}

National Cancer Institute

\section{Source}

National Cancer Institute. Focal Spot Size. NCI Thesaurus. Code C69242.

The size of the focal spot created by an X-ray tube. 